\title{
Perubahan Lahan Mangrove di Pesisir Muara Gembong, Bekasi, Jawa Barat
}

\author{
Alin Maulani*, Nur Taufiq-SPJ, Ibnu Pratikto \\ Departemen IImu Kelautan, Fakultas Perikanan dan IImu Kelautan, Universitas Diponegoro \\ JI. Prof. H. Soedarto S.H, Tembalang, Semarang, Jawa Tengah 50275 Indonesia \\ *Corresponding author e-mail : alinmaulani98@gmail.com
}

\begin{abstract}
ABSTRAK: Kecamatan Muara Gembong adalah wilayah dengan ekosistem mangrove yang cukup luas dan tersebar. Mangrove adalah kelompok jenis tumbuhan yang tumbuh di sepanjang garis pantai tropis sampai subtropis di suatu lingkungan yang mengandung garam dan bentuk lahan berupa pantai dengan reaksi tanah anaerob. Kondisi ekosistem mangrove sangat peka terhadap gangguan dari luar terutama dari kegiatan pencemaran, konversi hutan mangrove menjadi kawasan non-hutan, ekploitasi hasil mangrove yang berlebihan sehingga terjadi dinamika pada luasan lahannya. Perubahan yang terjadi pada ekosistem mangrove ini dapat berupa penambahan, pengurangan, dan lahan yang tetap. Metode yang dilakukan pada penelitian ini berupa pengolahan data satelit citra Sentinel 2A, Landsat 8, dan Landsat 5 untuk menganalisa sebaran mangrove pada tahun 2009,2014 , dan 2019 , serta perubahan yang terjadi. Validasi data dilakukan dengan pengamatan kawasan langsung di lokasi penelitian berdasarkan pengolahan data yang telah dilakukan. Hasil pengolahan data menunjukan di Kecamatan Muara Gembong pada tahun 2009-2019 diketahui terjadi penambahan luasan lahan mangrove sebesar 1017,746 ha dan pengurangan luasan mangrove sebesar 275,37 ha. Selain itu, terdapat pula lahan mangrove yang tetap bertahan pada kurun waktu $2009-2019$ seluas 255,057 ha. Sehingga perubahan lahan mangrove yang terjadi di Kecamatan Muara Gembong cenderung mengalami pertambahan luasan lahan mangrove, yaitu sebesar $66 \%$ lahan mangrove yang bertambah.
\end{abstract}

Kata kunci: Mangrove; Sentinel 2A; Landsat; Muara Gembong

\section{The Changes of Mangrove Area on the Coast of Gembong, Bekasi, West Java}

\begin{abstract}
Muara Gembong Subdistrict is an area with a wide and scattered mangrove ecosystem. Mangroves are a group of plant species that grow along tropical to subtropical coastlines in an environment that contains salt and landforms in the form of beaches with anaerobic soil reactions. The condition of mangrove ecosystems is very sensitive to outside disturbances, especially from pollution activities, conversion of mangrove forests to non-forest areas, excessive exploitation of mangrove products resulting in dynamics in the area of land. Changes that occur in this mangrove ecosystem can be in the form of addition, subtraction, and permanent land. The method used in this research is the processing of Sentinel 2A, Landsat 8, and Landsat 5 satellite image data to analyze the distribution of mangroves in 2009, 2014 and 2019, and the changes that occur. Data validation is done by direct observation of the area at the research location based on data processing that has been done. The results of data processing showed that in Muara Gembong Subdistrict in 2009-2019 it was known that there was an increase in the area of mangrove land by 1017, 746 ha and reduction in mangrove area by 275.37 ha. In addition, there are also mangrove lands that have survived in the period 2009-2019 covering 255,057 ha. So that changes in mangrove land that occur in Muara Gembong District tend to experience an increase in the area of mangrove land, which is equal to $66 \%$ of the mangrove land that is increasing.
\end{abstract}

Keywords: Mangrove; Sentinel; Landsat; Gembong Estuary

\section{PENDAHULUAN}

Ekosistem mangrove di wilayah tropis dan subtropis mempunyai peran yang sangat penting dalam melindungi adanya erosi di wilayah pesisir dan menjaga fungsi hidrologis di wilayah tersebut, sehingga dapat berfungsi untuk sebagai stabilator garis pantai dan juga berperan dalam penambahan lahan pantai. Kondisi ekosistem mangrove sangat peka terhadap gangguan dari luar terutama akibat praktik pengelolaan sumberdaya laut yang tidak ramah lingkungan, seperti dari 
kegiatan pencemaran, konversi ekosistem mangrove menjadi kawasan non-hutan seperti pemukiman, tambak serta ekploitasi hasil mangrove yang berlebihan (Syamsie et al., 2018). Kerusakan hutan mangrove disebabkan dua hal yaitu aktivitas manusia dan faktor alam. Negara Indonesia memiliki ekosistem mangrove terluas, akan tetapi laju deforestrasi ekosistem mangrove terjadi pula, yang merupakan permasalahan rusaknya hutan mangrove.

Inventarisasi mangrove secara spasial perlu dilakukan untuk mengetahui tingkat perubahan luasan ekosistem mangrove dari waktu ke waktu, sehingga memudahkan pemilihan langkah yang tepat dalam pengambilan kebijakan terkait dengan konservasi kawasan ekosistem mangrove. Pelestarian ekosistem mangrove di wilayah Indonesia dapat dilakukan dengan mengetahui perubahan luas hutan mangrove, sehingga dapat meningkatkan pengetahuan mengenai kondisi ekosistem mangrove di wilayah tersebut.

Ekosistem mangrove adalah salah satu obyek yang bisa diidentifikasi dengan menggunakan teknologi penginderaan jauh (Kustandiyo et al., 2014). Penginderaan jauh merupakan teknik atau ilmu pengetahuan yang menjelaskan tentang sesuatu obyek tanpa menyentuhnya. Teknologi ini dapat pula diartikan sebagai kegiatan perolehan informasi tentang permukaan bumi dengan menggunakan citra yang diperoleh dari dirgantara menggunakan energi elektromagnetik pada satu atau beberapa bagian spektrum elektromagnetik yang dipantulkan maupun dipancarkan dari permukaan bumi (Hartono, 2010).

Kecamatan Muara gembong memiliki potensi ekosistem mangrove yang cukup luas dan dapat dijadikan wilayah penyangga untuk mengurangi potensi dampak pemanasan global. Kawasan hutan mangrove di Muara Gembong relatif cukup baik dan saat ini ditetapkan sebagai kawasan hutan lindung (Ambinari et al., 2016). Namun, di beberapa kawasan hutan mangrove di Kecamatan Muara Gembong ini terus mengalami perubahan berupa penambahan dan pengurangan luasan. Kondisi hutan mangrove secara utuh, informasi mengenai dinamika perubahan tutupan hutan mangrove harus diketahui. Inventarisasi mangrove dan dinamika perubahan hutan mangrove, serta kajian mengenai kondisi perubahan yang terjadi di Kecamatan Muara Gembong masih belum tersedia secara lengkap.

Penelitian ini dilakukan untuk mengetahui persebaran lahan mangrove di Kecamatan Muara Gembong Kabupaten Bekasi pada tahun 2009, 2014, dan 2019, serta menganalisis perubahan lahan mangrove yang terjadi di Kecamatan Muara Gembong Kabupaten Bekasi pada tahun 20092019 yang diharapkan dapat memberikan informasi bagi Pemerintah Daerah Provinsi Jawa Barat dan stakeholder terkait maupun bagi kalangan akademisi dan dunia ilmu pengetahuan, serta dapat dijadikan sebagai dasar atau pegangan dalam pengambilan kebijakan, terutama yang berhubungan dengan pengelolaan dan pengembangan kegiatan di wilayah pesisir pantai.

\section{MATERI DAN METODE}

Materi yang digunakan dalam penelitian ini merupakan data vegetasi mangrove yang didapatkan melalui pengolahan citra satelit dan pengambilan data lapangan. Citra satelit yang digunakan adalah citra satelit Sentinel 2A perekaman 2 September 2019, citra satelit landsat 8 perekaman 13 September 2014, dan citra satelit landsat 5 perekaman 29 Juli 2009 yang diperoleh melalui situs resmi (earthexplorer.usgs.gov).

Penelitian ini dilakukan dengan tahapan prosedur kerja berupa pengolahan citra dan pengambilan data di lapangan yang dilaksanakan pada September 2019-Mei 2020. Tahapan pengambilan data lapangan dilaksanakan pada Bulan Desember 2019 di pesisir Kecamatan Muara Gembong Kabupaten Bekasi yang bertujuan untuk memvalidasi hasil pengolahan data citra satelit dan mengetahui kondisi vegetasi mangrove.

Interpretasi citra penginderaan jauh dilakukan untuk mengetahui informasi perubahan lahan mangrove yang terjadi menggunakan tahun yang berbeda berdasarkan nilai digital yang terekam pada data penginderaan jauh. Data sekunder dalam penelitian ini berupa rupa bumi Indonesia, peta batas wilayah administrasi Kecamatan Muara Gembong, serta dokumen Rencana Tata Ruang Wilayah Kabupaten Bekasi untuk kesesuaian Rencana Tata Ruang Wilayah Kabupaten Bekasi dengan kondisi mangrove di Kecamatan Muara Gembong, wawancara lapangan secara langsung mengenai kondisi mangrove, dan data historis perkembangan pengelolaan kawasan mangrove di Kecamatan Muara Gembong. 
Metode survey lapangan dilakukan untuk mengetahui hasil interpretasi sebagai bentuk dari verifikasi data yang telah diolah melalui citra satelit (Wirandha et al., 2015). Penentuan lokasi survey lapangan berdasarkan keterwakilan lokasi kajian untuk daerah-daerah mangrove yang mengalami perubahan, sesuai dengan hasil klasifikasi atau pengolahan citra. Pengecekan dilakukan dengan bantuan Global Positioning System (GPS). Titik pengamatan ditentukan dengan metode purposive sampling. Dilakukan pengambilan beberapa titik sampel (stasiun) yang akan didatangi, kemudian dilakukan pendataan, pengamatan serta pencatatan informasi penting. Data yang diambil adalah data rekam koordinat titik pengamatan lapangan dari GPS, kondisi tutupan lahan sekitar titik lapangan yang dilengkapi dan didokumentasikan menggunakan kamera digital, serta menganalisis faktor penyebab perubahan dan dampak perubahan lahan mangrove yang terjadi terhadap masyakarat di lokasi penelitian melalui wawancara kepada masyarakat.

Tahapan yang dilakukan dalam pengolahan citra dengan teknologi penginderaan jauh untuk menghasilkan peta sebaran dan perubahan lahan mangrove, yaitu : Pengkoreksian citra yang dilakukan dengan melakukan koreksi geometrik pada citra yang akan digunakan dalam analisis data penelitian. Koreksi geometrik pada citra adalah langkah untuk memperbaiki kesalahan perekaman secara geometrik agar citra yang dihasilkan mempunyai sistem koordinat dan skala yang seragam (Lukiawan et al., 2019), Kemudian dilakukan pemotongan citra agar analisa data terpusat pada objek dan daerah yang akan diteliti, dan memperkecil file yang digunakan serta mempercepat proses-proses dalam software penginderaan jauh apabila dibandingkan dengan mengolah satu scene penuh (Niagara et al., 2020). Komposit Citra dilakukan untuk keperluan analisis dengan memilih 3 buah band/kanal dan dikombinasikan sesuai dengan karakteristik spektral masing-masing band/kanal. Komposit citra yang dapat digunakan untuk menganalisis lahan mangrove merupakan kombinasi band NIR (near infrared), green, dan SWIR untuk visualisasi vegetasi (BIG, 2017). Vegetasi mangrove berwarna merah kecoklatan yang sangat kontras dengan objek lain disekitarnya. Terakhir, metode overlay (tumpang susun) digunakan untuk mengetahui besar perubahan luasan vegetasi mangrove. Metode ini dilakukan dengan melakukan tumpang susun pada citra yang telah diolah pada perekaman tahun 2009, 2014, dan 2019. Berdasarkan analisa citra dan hasil pengamatan lapangan, kemudian menghitung luasan serta prosentase dari total masing-masing lahan mangrove. Evaluasi perubahan suatu kelas dilihat berdasarkan perubahan luasan yang terjadi.

\section{HASIL DAN PEMBAHASAN}

Hasil digitasi dan pengklasifikasian sebaran mangrove pada tahun 2009, 2014, dan 2019 kemudian di overlay agar menjadi 1 layer, sehingga dapat terlihat dengan jelas perubahan yang terjadi. Band yang digunakan pada penelitian ini adalah kombinasi band NIR, SWIR, dan Green yang diatur pada kanal Red, Green, dan Blue. Perubahan dapat terlihat pada Gambar 2 yang menunjukan adanya penambahan dan pengurangan pada sejumlah wilayah lahan mangrove, serta terdapat lahan mangrove yang tetap bertahan sejak tahun 2009 hingga 2019.

Berdasarkan pengolahan data yang dilakukan dengan menggunakan citra satelit, diperoleh perkiraan luasan lahan mangrove di Kecamatan Muara Gembong pada tahun 2009, 2014, dan 2019 di setiap desa ditampilkan dalam Gambar 5 yang menujukan bahwa terjadi perubahan luasan lahan mangrove di setiap desa di Kecamatan Muara Gembong pada tahun 2009, 2014, dan 2019. Desa Pantai Harapan Jaya mengalami pertambahan luas lahan pada tahun 2009-2014 dengan luas lahan mangrove 72,20 ha menjadi 213,37 ha, namun mengalami pengurangan luas lahan pada tahun 2014-2019 menjadi 154,15 ha. Desa Pantai Mekar mengalami pengurangan luas lahan pada tahun 2009-2014 dengan luas lahan mangrove 134,55 ha menjadi 145,7 ha dan mengalami penambahan luas lahan pada tahun 2014-2019 menjadi 176,8 ha. Desa Pantai Bahagia mengalami pengurangan luas lahan pada tahun 2009-2014 dengan luas lahan mangrove 312,93 ha menjadi 245,35 ha dan mengalami penambahan luas lahan pada tahun 2014-2019 menjadi 390,36 ha. Desa Pantai Bakti mengalami pertambahan luas lahan mangrove dari tahun 2009 dengan luas 11,99 ha bertambah menjadi 19,96 ha pada tahun 2014 , dan menjadi 70,72 ha pada tahun 2019. Desa Pantai Sederhana mengalami pengurangan luas lahan pada tahun 20092014 dengan luas lahan mangrove 176,93 ha menjadi 145,66 ha dan mengalami penambahan 
luas lahan pada tahun 2014-2019 menjadi 193,8115 ha. Sedangkan Desa Jayasakti tidak memiliki area lahan mangrove karena tidak berbatasan dengan wilayah pantai.

Lahan mangrove terluas terdapat di Desa Pantai Bahagia. Sedangkan Desa Jayasakti tidak memiliki area lahan mangrove. Grafik yang ditampilkan pada gambar 5 menunjukan terjadi perubahan luas lahan mangrove setiap tahunnya pada setiap desa di Kecamatan Muara Gembong. Perubahan luas lahan mangrove di Kecamatan Muara Gembong terjadi penambahan dan pengurangan luasan, namun terdapat pula area mangrove yang tetap bertahan atau terus ada dari tahun 2009-2014. Luas perubahan lahan yang terjadi di Kecamatan Muara Gembong pada tahun 2009-2014 ditunjukan pada Gambar 6.

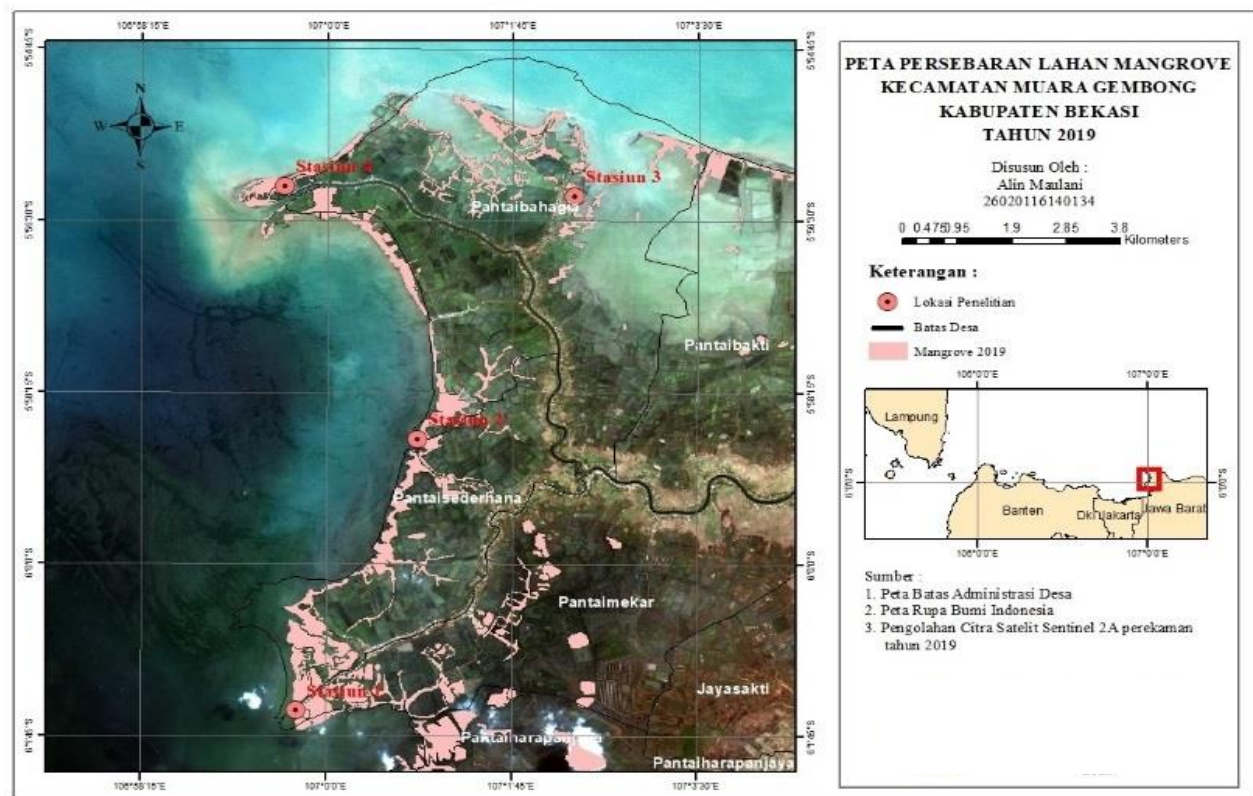

Gambar 1. Sebaran Mangrove Kecamatan Muara Gembong Kabupaten Bekasi tahun 2019 menggunakan citra satelit Sentinel 2A dengan waktu perekaman 2 September 2019.

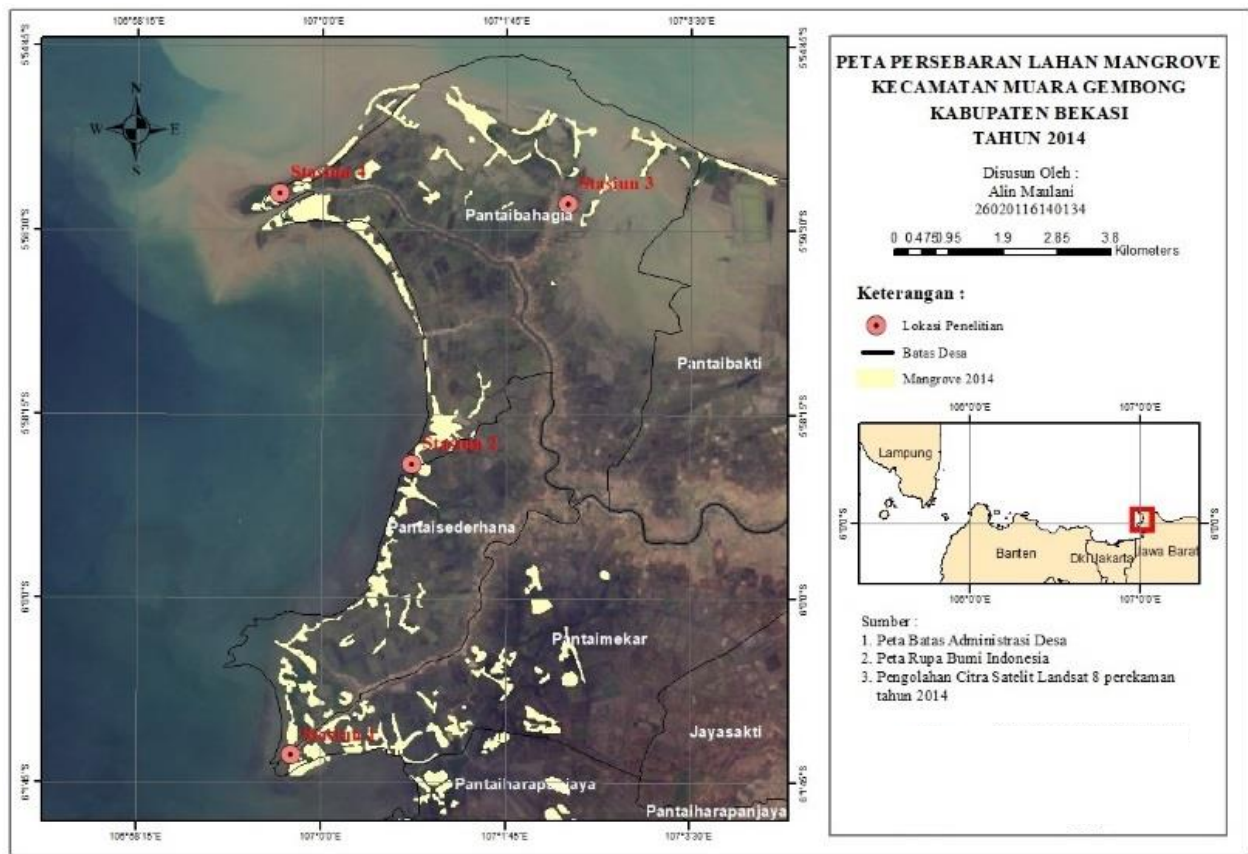

Gambar 2. Sebaran Mangrove Kecamatan Muara Gembong Kabupaten Bekasi tahun 2014 menggunakan citra satelit Landsat 8 dengan waktu perekaman 13 September 2014. 


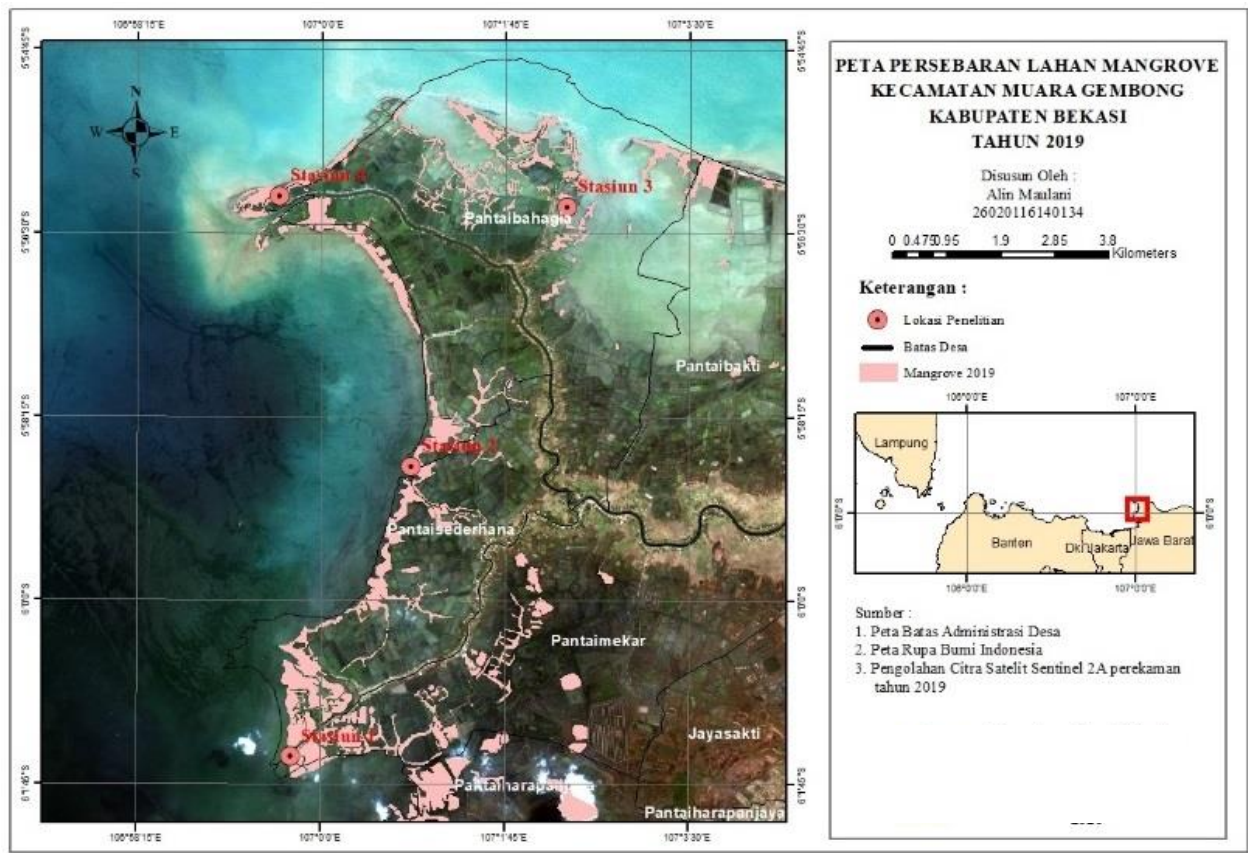

Gambar 3. Sebaran Mangrove Kecamatan Muara Gembong Kabupaten Bekasi tahun 2009 menggunakan citra satelit landsat 5 dengan waktu perekaman 29 Juli 2009.

Berdasarkan data luas lahan mangrove diperoleh persentase persentase perubahan luasan lahan mangrove di Kecamatan Muara Gembong pada tahun 2009-2019 pada gambar 6, dimana area lahan mangrove di Kecamatan Muara Gembong bertambah sebesar 66\% dari tahun 20092019 , mengalami pengurangan sebesar $18 \%$ dan area mangrove yang tetap bertahan dari tahun 2009-2019 sebesar $16 \%$.

Kawasan lahan mangrove yang terdapat di Kecamatan Muara Gembong setiap desanya mengalami perubahan dari tahun 2009-2019 berupa penambahan luasan, pengurangan, dan lahan mangrove yang tetap bertahan. Penambahan luasan lahan mangrove dominan terjadi di daerah dekat dengan muara sungai dan yang berbatasan langsung dengan perairan yang menghadap ke Teluk Jakarta. Pengurangan luasan lahan mangrove banyak terjadi pada daerah lahan mangrove yang berada di sekitar pertambakan dan pemukiman masyarakat, serta lahan mangrove yang berbatasan langsung dengan perairan yang menghadap ke Laut Jawa. Lahan mangrove yang berada di kawasan mangrove lebat yang berbatasan langsung dengan wilayah perairan laut pada tahun 2009-2019 sebagian besar tetap bertahan.

Berdasarkan penelitian yang telah dilakukan, diperoleh estimasi luasan lahan mangrove yang berada di Kecamatan Muara Gembong, dimana terjadi pertambahan lahan pada tahun 20092019. Hal ini sejalan dengan usaha pemerintah dalam penetapan rencana tata ruang yang menetapkan kawasan konservasi mangrove di Kecamatan Muara Gembong dan mulai melakukan usaha penanaman mangrove di beberapa lokasi desa seperti di Desa Pantai Mekar, Desa Pantai Bakti, Desa Pantai Bahagia dan Desa Pantai Harapan jaya.

Menurut data yang diperoleh dari pengolahan data yang dilakukan Desa Pantai Bahagia dan Desa Pantai Sederhana mengalami pengurangan lahan pada tahun 2009-2014 yang diakibatkan alih fungsi lahan mangrove menjadi area pertambakan dan faktor alam berupa abrasi dan usia mangrove. Desa-desa tersebut mengalami pertambahan luasan lahan mangrove kembali pada tahun 2014-2019 yang dikarenakan mulai dilakukannya penanaman mangrove dan rehabilitasi area mangrove, sehingga luas lahan mangrove yang bertambah cukup signifikan.

Desa Pantai Bakti yang berada di perairan Laut Jawa menjadi wilayah yang rentan terkena abrasi, sehingga menjadi wilayah yang seringkali dilakukan penanaman mangrove, seperti di Pantai Muara Bungin, Desa Pantai Bakti. Hal itu menyebabkan luas lahan mangrove yang terus mengalami pertambahan. Saat ini, Pantai Muara Bungin di Desa Pantai Bakti ini menjadi salah satu pantai wisata di Kecamatan Muara Gembong. Hal ini juga terjadi di Desa Pantai Mekar, 
dimana terus terjadi pertambahan luasan lahan mangrove pada tahun 2009-2019. Pertambahan luasan lahan mangrove yang terjadi di Desa Pantai Mekar seiring dengan kegiatan penanaman mangrove karena penetapan daerah ekowisata mangrove yang berada di kawasan mangrove Desa Pantai Mekar. Kegiatan ini merupakan kerja sama antara pihak Perhutani dengan PT. Pertamina EP Asset Tambun Field Perum Perhutani untuk memaksimal wilayah konservasi mangrove yang menunjang perekonomian masyarakat.

Desa Pantai Harapan Jaya mengalami pertambahan luasan lahan mangrove pada tahun 2009 hingga 2014 yang diakibatkan perkembangan mangrove secara alami dan penanaman mangrove di beberapa lokasi. Namun, pada tahun 2014-2019 lahan mangrove di Desa Pantai Harapan Jaya mengalami pengurangan luas lahan yang disebabkan adanya alih fungsi lahan mangrove menjadi pertambakan yang mengakibatkan berkurangnya vegetasi mangrove di desa tersebut.

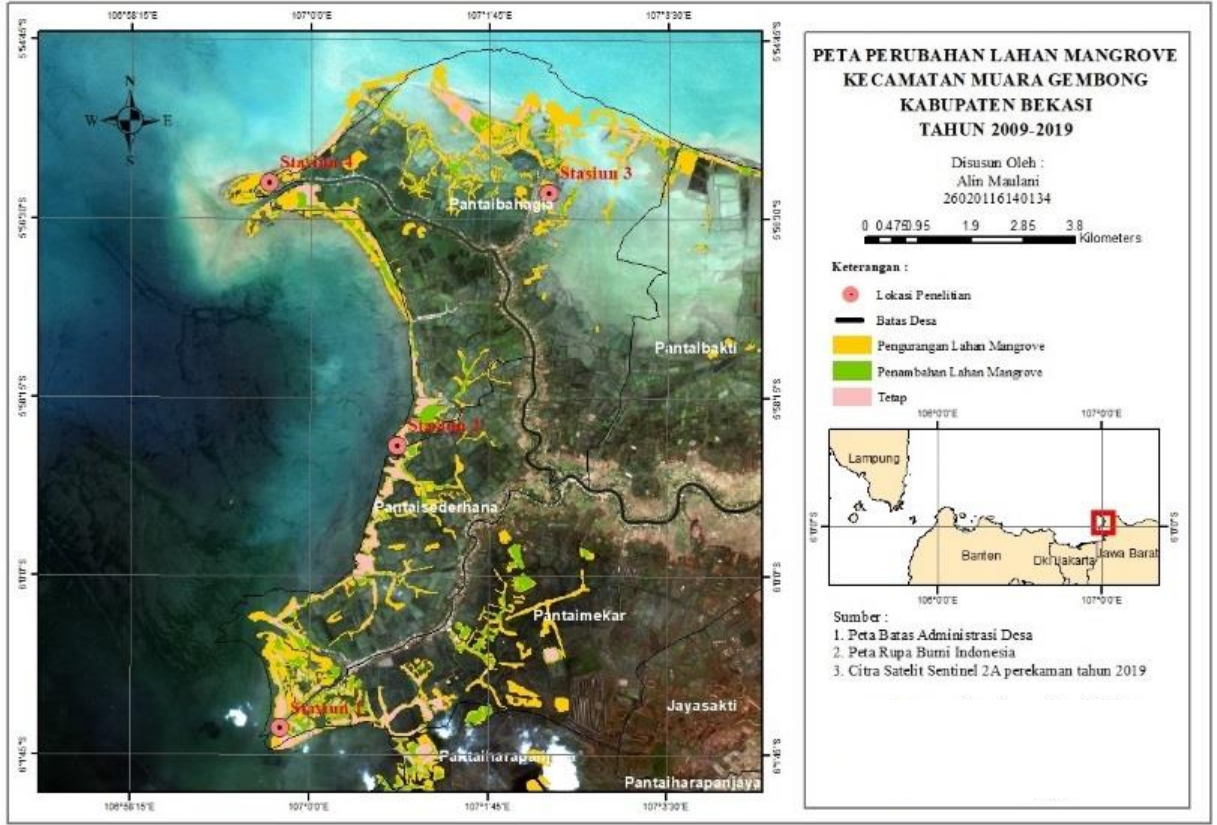

Gambar 4. Perubahan Lahan Mangrove Kecamatan Muara Gembong Kabupaten Bekasi Tahun 2009-2019.

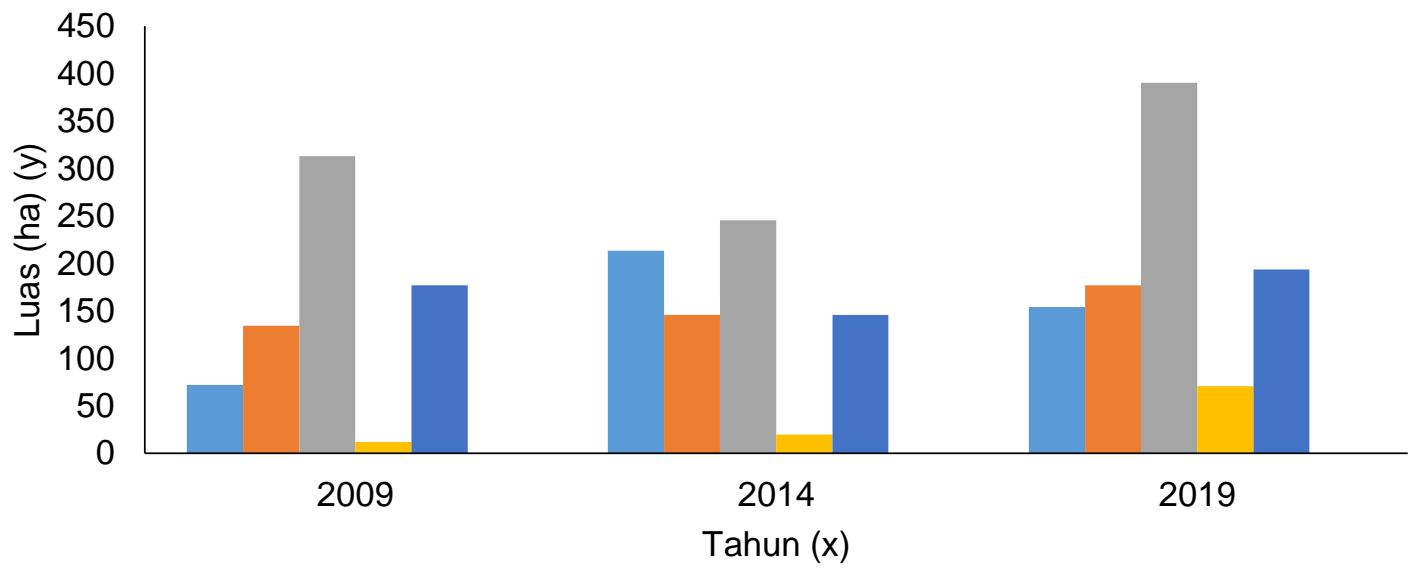
- Desa Pantai Harapan Jaya
- Desa Pantai Mekar
- Desa Pantai Bahagia
Desa Pantai Bakti
- Desa Pantai Sederhana
- Desa Jayasakti

Gambar 5. Grafik Perubahan Luasan Lahan Mangrove Kec. Muara Gembong Kab. Bekasi Tahun 2009, 2014, dan 2019. 
Peningkatan luasan lahan mangrove terjadi seriring dengan adanya upaya-upaya merehabilitasi dan revitalisasi vegetasi mangrove yang terdapat di Kecamatan Muara Gembong, terutama lahan mangrove yang kondisinya sudah mengalami kerusakan. Guna mendukung kegiatan rehabilitasi dan revitalisasi lahan mangrove dilakukan kegiatan pembuatan persemaian dan pembibitan tanaman mangrove yang selanjutnya dilakukan kegiatan penanaman mangrove di wilayah pesisir telah mengalami penurunan kualitas lingkungannya (Sari et al., 2018). Dengan demikian diharapkan lingkungan pesisir tersebut akan menjadi lebih baik dan dapat meningkatkan luas hutan mangrove. Hal ini dilakukan oleh berbagai pihak, termasuk di dalamnya masyarakat setempat, pemerintah daerah, dan instansi terkait yang melakukan kerja sama.

Bertambah luasnya lahan mangrove juga dipengaruhi oleh faktor persebaran biji mangrove yang tumbuh subur dan menyebar di sekitar daerah yang hijau (hutan mangrove primer). Menurut Indriatmoko et al. (2019), vegetasi mangrove di bagian pesisir terdepan Kecamatan Muara Gembong lebih banyak ditumbuhi oleh mangrove mayor, seperti Avicennia marina, Avicennia officinalis, Avicennia alba, Sonneratia alba, Sonneratia caseolaris, Rhizophora apiculata serta Rhizophora mucronata. Hal ini menunjukkan regenerasi spesies ini cukup potensial di pesisir terdepan Muara Gembong.

Berkurangnya luasan lahan mangrove di Kecamatan Muara Gembong dipengaruhi oleh aktifitas manusia berupa perluasan areal tambak yang kian meningkat setiap tahunnya. Selain itu, berkurangnya luas area mangrove juga disebabkan adanya konversi lahan menjadi sawah, kebun, bahkan salah satu faktor yang menyebabkan berkurangnya lahan hutan mangrove di kawasan Muara Gembong adalah kebutuhan area pemukiman. Ernawati (2016) menyatakan banyak masyarakat dari daerah lain seperti Banten, Indramayu, Tegal, dan masyarakat pinggiran Jakarta yang migrasi ke kawasan pesisir Muara Gembong. Desa Pantai Harapan Jaya misalnya, terjadi pengkorvesian lahan mangrove menjadi area pertambakan yang menyebabkan berkurangnya luasan lahan mangrove di Desa tersebut.

Kerusakan alamiah lahan mangrove juga menjadi faktor berkurangnya luas lahan mangrove di Kecamatan Muara Gembong. Pesisir Muara Gembong merupakan bagian wilayah dari Kabupaten Bekasi di Pantai Utara Jawa Barat yang mengalami degradasi hutan mangrove cukup serius (Wulandari et al., 2019). Peristiwa alam seperti adanya gelombang besar pada musim angin timur dan musim kemarau yang berkepanjangan sehingga dapat menyebabkan rusaknya area lahan mangrove.

Laju abrasi yang cukup tinggi ditambah dengan topografi pesisir Muara Gembong yang landai (dataran rendah dengan elevasi < 50) disinyalir merupakan faktor pendukung terjadinya banjir pasang (rob) dan intrusi air laut dengan frekuensi yang cukup tinggi. Menurut Indriatmoko et al. (2019), hal ini dibuktikan dengan hilangnya 3 dusun desa di sekitar pesisir Muara Gembong dan telah berpindah-pindahnya lokasi tempat pelelangan ikan (TPI) dalam beberapa tahun terakhir.

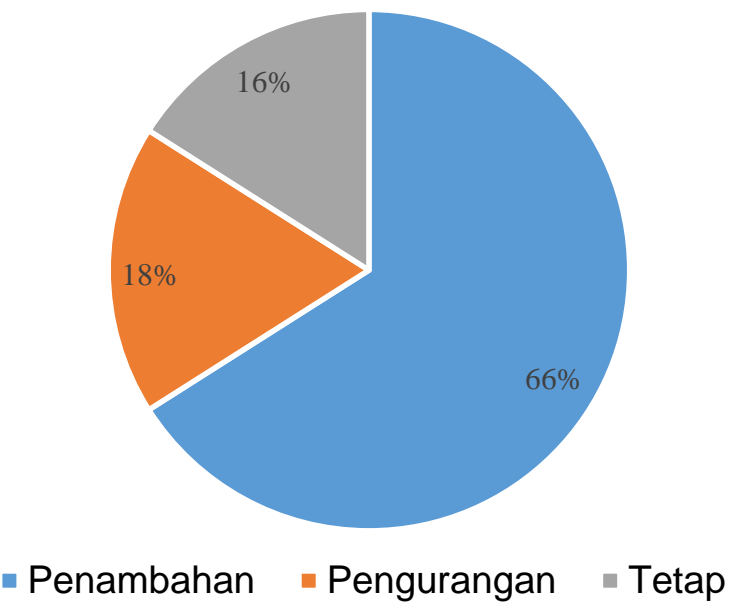

Gambar 6. Persentase Perubahan Luasan Lahan Mangrove Kec. Muara Gembong Kab. Bekasi Tahun 2009-2019. 
Masyarakat yang tinggal di wilayah Muara Gembong sebagian besar adalah nelayan, baik nelayan tangkap maupun tambak (Suwargana, 2008), sehingga area mangrove menjadi salah satu sumberdaya penunjang perekonomian masyarakat di Kecamatan Muara Gembong, sehingga perubahan luasan lahan mangrove dapat berdampak pada perekonomian masyarakatnya. Terjadinya degradasi lingkungan dan kerusakan ekosistem mangrove Muara Gembong secara masif memicu terjadinya bencana ekologi seperti abrasi, sedimentasi, intrusi air laut dan banjir rob. Namun, pertambahan lahan mangrove yang terjadi dimanfaatkan sebagian masyarakat untuk dijadikan sebagai lokasi wisata mangrove dan areal tambak alami yang dapat menyediakan hasil laut seperti kepiting beberapa jenis ikan dan juga rumput laut yang dibudidayakan oleh masyarakat.

\section{KESIMPULAN}

Berdasarkan penelitian yang telah dilakukan, diperoleh kesimpulan lahan mangrove di Kecamatan Muara Gembong mencakup wilayah yang luas dan tersebar di sepanjang pantai sepanjang pantai, sekitar sungai, muara sungai, bekas tambak, sekitar tambak, dan sekitar pemukiman. Luas lahan mangrove di Kecamatan Muara Gembong pada tahun 2009 seluas 708, 6 ha, bertambah pada tahun 2014 menjadi 770,08 ha, dan pada tahun 2019 menjadi seluas 985,85 ha. Terdapat pula area mangrove yang tetap bertahan atau terus ada dari tahun 2009-2019. Penambahan lahan yang terjadi pada tahun 2009 hingga 2019 di Kecamatan Muara Gembong seluas 10177,46 ha, pengurangan lahan sebesar 2753,75 ha, dan lahan mangrove yang tetap bertahan dalam sebesar 2550,57 ha. Sehingga luasan lahan mangrove di Kecamatan Muara Gembong pada tahun 2009-2019 didominasi oleh pertambahan luasan, yaitu sebesar $66 \%$.

\section{DAFTAR PUSTAKA}

Ambinari, M., Darusman, D., Alikodra, H.S., \& Santoso, N. 2016. Penataan Peran Para Pihak dalam Pengelokaan Hutan Mangrove di Perkotaan : Studi Kasus Pengelolaan Hutan Mangrove di Teluk Jakarta. Jurnal Analisis Kebijakan, 13(1):29-40.

Badan Informasi Geospasial. 2017. Pedoman Teknis Pengumpulan dan Pengolahan Data Geospasial Mangrove. Cibinong.

Ernawati, A. 2016. Analisis Potensi Pantai Muara Beting Bekasi Menjadi Kawasan Wisata Mangrove. Temu Ilmiah IPLBI 2016. Situs https://temuilmiah.iplbi.or.id/wpcontent/ uploads/2016/12/IPLBI2016-F-001-008-Analisa-PotensiKawasan-Wisata-Pantai-Muara-

Beting-Bekasi.pdf (30 April 2019).

Hartono. 2010. Penginderaan Jauh dan Sistem Informasi Geografi serta Aplikasinya di Bidang Pendidikan dan Pembangunan. Seminar Nasional Penginderaan Jauh dan SIG.

Indriatmoko, M.H. Jayawiguna \& Riswanto. 2019. Karakteristik dan Indeks Kerentanan Mangrove di Pesisir Kecamatan Muara Gembong. Jakarta, AMAFRAD Press - Badan Riset dan Sumber Daya Manusia Kelautan dan Perikanan.

Kustandiyo, H., Sukojo, B.M. \& Parwati, E. 2014. Studi Tingkat Kerapatan Mangrove Menggunakan Indeks Vegetasi. Jurnal Geoid, 9(2):101-107.

Lukiawan, R., Purwanto, E.H. \& Ayundyahrini, M. 2019. Standar Koreksi Geometrik Citra Satelit Resolusi Menengah dan Manfaat Bagi Pengguna. Jurnal Standardisasi, 21(1):45-54.

Niagara, Y., Ernawati, A \& Purwandari E.P. 2020. Pemanfaatan Citra Penginderaan Jauh Untuk Pemetaan Klasifikasi Tutupan Lahan Menggunakan Metode Unsupervised K-Means Berbasis Web GIS (Studi Kasus Sub-DAS Bengkulu Hilir). Jurnal Rekursif, 8(1):100-110.

Sari Y.P., Salampessy, M.L., \& Lidiawati, I. 2018. Persepsi Masyarakat Pesisir dalam Pengelolaan Ekosistem Hutan Mangrove di Muara Gembong Bekasi Jawa Barat. Jurnal Perennial., 14(2):78-85. 
Suwargana, N. 2008. Analisis Perubahan Hutan Mangrove Menggunakan Data Penginderaan Jauh di Pantai Bahagia, Muara Gembong, Bekasi. Jurnal Penginderaan Jauh, 5:64-74.

Syamsie, I.F., Nugraha, A.Z., Nugraheni, C.T., \& Salmana, W. 2018. Kajian Perubahan Tutupan Lahan di Ekosistem Mangrove Pantai Timur Surabaya. Jurnal Media Konservasi, 23(2):122131.

Wirandha F.S., Marwan \& Nizamuddin. 2015. Klasifikasi Penggunaan Lahan Menggunakan Citra Satelit Spot-6 di Kabupaten Aceh Barat Daya dan Aceh Besar. Seminar Nasional dan Expo Teknik Elektro.

Wulandari, Y.P., Raysina, N. \& Muningsih, D. 2019. Kajian Dampak Inovasi Mangrove Protector pada Ekowisata Mangrove Desa Pantai Mekar. Jurnal Resolusi Konflik, 3(1):43-50. 